\title{
Non-invasive sub-surface analysis of the male portrait underlying the Titian's Studio Ecce Homo
}

\author{
Svetlana Gasanova* ${ }^{*}$, Nikolas Bakirtzis and Sorin Hermon
}

\begin{abstract}
The present study discusses new research on the analysis of a portrait of a male figure discovered under the painting of Ecce Homo, attributed to the studio of Titian (ca. 1488-1576), with an estimated date in the 1550s. The portrait was examined with non-invasive methods: X-ray radiography (XRR), digital microscopy and micro-XRF. The examination of XRR images exposed the details of the painting's underlying depiction, which according to the details preserved appears to be a completed or nearly finished portrait of a standing man. The application of digital microscopy on the Ecce Homo painting's cracks enabled the identification of the work's stratigraphy. Micro-XRF performed on selected spots allowed to identify lead white, vermilion, red iron oxide, umber, carbon black and copper green in the underlying portrait. The described investigation methodology was guided by the close visual analysis of the Ecce Homo work and proved to be effective in the identification of the pigments of the hidden painting and the reconstruction of its colour palette.
\end{abstract}

Keywords: Hidden painting, Micro-XRF, X-ray radiography, Digital microscopy, Titian, Ecce Homo

\section{Introduction}

The reuse and repainting of canvases was a common practice in artists' workshops. Artists often recycled these materials for various reasons such as unsuccessful compositions, unpaid commissioned paintings or unsatisfied clients. The number of discoveries related to reused canvases hiding unknown preparatory drawings or even finished paintings under later applied compositions is constantly growing [1-5]. This is mainly due to non-invasive imaging methods that are now at the disposal of scientists and are capable of reading the hidden compositions. Among these, X-ray radiography (XRR) and infrared reflectography (IRR) are the most conventional techniques for the identification and study of underlying paintings $[6,7]$. These are fast and straightforward methods able to image hidden compositions, provided that X-ray or IR opaque materials are present in

\footnotetext{
*Correspondence: s.gasanova@cyi.ac.cy

The Science and Technology for Archaeology Research center

(STARC), The Cyprus Institute, 20 Konstantinou Kavafi street, Aglantzia,

2121 Nicosia, Cyprus
}

the pictorial layers. However, the reading of XRR and IRR images might be complicated as the images result from overlap of all the pictorial layers. The recently introduced terahertz $(\mathrm{THz})$ imaging technique overcomes this obstacle by yielding a 3D structure. Being a complementary technique to XRR and IR, in terms of pigment identification, $\mathrm{THz}$ imaging also allows the collection of data on the thickness of various pictorial layers $[8,9]$. Another important method for the study of hidden paintings is neutron activation autoradiography (NAAR), which allows the identification of a wide range of pigments [10]. Nonetheless, apart from the use of radioactive sources, NAAR's significant disadvantage is the absence of portable devices requiring transportation of the analysed paintings to the dedicated laboratory. Providing additional research tools to address the challenges presented in the study of paintings hidden under later pictorial compositions, the scanner X-ray fluorescence (XRF) technique has the potential to not only reveal contours of underlying works, but also to yield maps of elemental distribution, thus, suggesting the presence of certain pigments [11-16]. 
The above described techniques are powerful tools, which are rapidly developing and conquering the field of the heritage science. However, there are only a few laboratories, which are able to afford and support the development of such advanced infrastructure. Thus, the technical examination of works of art and hidden paintings in particular, has become a challenge for laboratories with limited scientific facilities. In the present study, we propose a multi-technique approach based on the integration of XRR as the first step in the delineation of the contours of hidden compositions, digital microscopy for the examination of painting stratigraphy and microXRF for pigment identification. The aim of the study is to reveal the potential of the proposed approach in the identification of the compositional elements and the pigments of hidden paintings.

The analysed case study is the painting of Ecce Homo (Fig. 1a, oil on canvas, $94 \times 107.5 \mathrm{~cm}$ ), attributed to Titian's studio with a suggested date in the 1550s [17]. The work depicts the theme of Ecce Homo ("behold the man"), a topic explored by Titian in the later phase of his artistic career in a series of paintings $[18,19]$; at least five other known works are now kept in Saint Louis, Dresden, The Prado, Munich and Hampton Court. The work, also identified as "Christ mocked", provides a close up view of the meeting of Pontius Pilate and Christ, a compositional perspective that departs from other versions of the topic featuring more distant views of the event such as his 1543 work, now at the Kunsthistorisches Museum in Vienna. In the examined work, the central figure of Christ is depicted naked, bound and crowned with a wreath of thorns. Standing along his left side is Pilate, dressed in a lavish costume and wearing an elaborate turban-like headpiece. He is raising his left hand with an open palm, a gesture of self-exoneration that resonates with the biblical narrative of the depicted scene. To the right of Christ's figure stands a youth, presumably a boy. He is wearing a bright blue headscarf, while a bright red earing adorns his right ear. The youth is holding the rope bounding Christ's hands. Behind this figure and over Christ's right shoulder is the head of another participant, seemingly a man holding a pole with a lighting device in the form of a brazier containing bright red coals.

Prior to its acquisition by the current owner, the painting underwent preliminary XRR, which revealed an underpainting depicting the portrait of a standing man. This work was overpainted with the Ecce Homo at a $180^{\circ}$ angle. No further art historical information was available on the initial painting in regards to its subject, colour or pigment composition. The present study is part of a complex technical examination of the Ecce Homo painting, involving the analysis of the preparation layers, canvas treatment, pigments, binding media, varnish, conservation state and history of restorations.

\section{Methods \\ $\mathrm{X}$-ray radiography}

The digital XRR was performed at the radiology department of the Mediterranean Hospital of Limassol. Images were obtained in transmission mode from a $\mathrm{Cu} \mathrm{X}$-ray tube operated at $30 \mathrm{kV}, 500 \mu \mathrm{A}$. The acquisition time was set to $20 \mathrm{~ms}$. The painting was positioned facing the digital detector (DX-D 40G, Agfa, $35 \times 45 \mathrm{~cm}$ ) with the distance between the X-ray source and the detector of $1.2 \mathrm{~m}$. Fifteen (15) images were taken in total, in order to cover the roughly $1 \mathrm{~m}^{2}$ of the canvas and its wooden frame. These were first processed with an X-ray medical imaging software (eFilm Workstation) and then exported into an
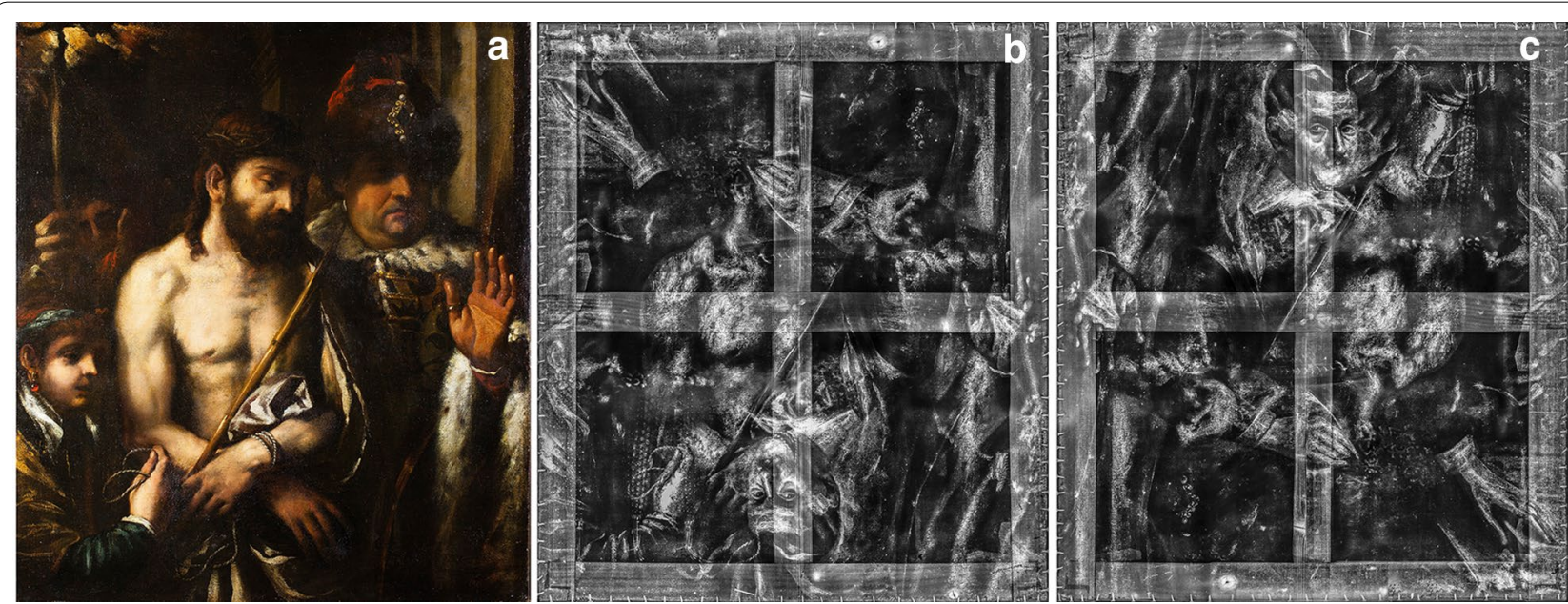

Fig. 1 The Ecce Homo painting: a visible image, $\mathbf{b}$ X-ray radiography image and $\mathbf{c}$ X-ray radiography image rotated at $180^{\circ}$ revealing the hidden portrait 
image processing software (Adobe Photoshop 2015) for final alignment and detection of features' contours.

\section{Digital microscopy}

The surface of the upper painting was photographed with a Hirox KH-8700 digital microscope at various magnifications $(35 \times-2500 \times)$ according to the target, using the dual illumination revolver zoom lenses. This test allowed to check the presence of underlying layers, their color as well as to study the pigment particles.

\section{XRF}

\section{$X R F$ conditions}

The XRF spectra were recorded with an ARTAX$200 \mu$-XRF spectrometer (Bruker), equipped with a molybdenum X-ray tube, an integrated CCD camera with sample illumination and laser spot, a silicon drift detector with a resolution of $<150 \mathrm{eV}$ and a $0.65 \mathrm{~mm}$ collimator. The X-ray tube was operated at $50 \mathrm{kV}$ and $700 \mu \mathrm{A}$ with an integration time of $90 \mathrm{~s}$. Prior to the current study, the effect of helium atmosphere on the detection of low- $Z$ elements was carried out by measuring various spots of the painting with and without helium flush. The spectra did not demonstrate any difference in the intensity of the low-Z elements, presumably due to the thick layer of varnish on the surface of Ecce Homo, which significantly attenuated the signal of light elements. Therefore, all XRF measurements were carried out in air atmosphere with a molybdenum filter. The energy to channel calibration was performed with a bronze standard, using the $\mathrm{Cu}$ and $\mathrm{Sn}-\mathrm{K} \alpha$ lines; the $\mathrm{Mn}-\mathrm{K} \alpha$ line of a manganese standard was used for the FWHM calibration. The obtained XRF spectra demonstrated variable intensities of $\mathrm{Pb} L \alpha$, $\mathrm{Cu} \mathrm{K} \alpha, \mathrm{Hg} \mathrm{L} \alpha, \mathrm{Mn} \mathrm{K} \alpha$ and $\mathrm{Fe} \mathrm{K} \alpha$ lines. The net areas of these lines were evaluated to study distributions of lead, copper, mercury, manganese and iron across the painting surface. The spectra acquisition and evaluation were performed with the Spectra 5.3 software.

\section{Selection of analyzed spots}

The XRF spectra were recorded in two ways: either directly from the exposed pictorial layers of underlying portrait in places, where the cracks and flaked areas of Ecce Homo were sufficiently big, or from the Ecce Homo surface. In the first case, XRF spectra reflected the information on elemental composition of only the lower painting excluding the necessity to isolate the signal from the upper painting. In the second case, the underlying portrait was not directly accessible and the XRF spectra acquired contained contributions of both the upper and the lower paintings. In order to facilitate the isolation of the signal coming from the lower painting, spots with presumably different colour (based on
$\mathrm{XRR}$ and microscopy observations) and pigment composition between the upper and the lower paintings were analyzed. To achieve this step of the process, the visible image was compared with the XRR image in every spot analyzed. For example, the area of man's left cuff executed with a white (based on microscopy observations) pigment corresponds to a dark brown background of Ecce Homo, which allows to suggest the presence of different pigments in the upper and the lower paintings. Additionally, we predominantly chose areas of the lower painting, which correspond to homogeneous areas of Ecce Homo. This allowed to assume the equal contribution of the upper painting signal in the resulting XRF spectra within the area of interest. For example, spectra from all spots in the area of man's left hand (lower painting) have equal contribution from the corresponding homogeneous area of Ecce Homo. Thus, the difference in spectra from spots within this area reflects the difference in the pigment composition of the lower painting.

\section{Results and discussions \\ Pictorial composition}

X-ray radiography (Fig. 1b, c) revealed the presence of an underlying portrait of a standing man executed at a $180^{\circ}$ angle in comparison to the visible Ecce Homo composition. The man is slightly turning his head to the right facing the viewer. His facial characteristics are clearly defined. He is a middle-age adult man with wrinkles and bags under his eyes. He has a broad and straight nose, broad forehead and piercing eyes directly engaging the viewer. He appears to have short hair and a short moustache can be tentatively identified. His tight lips and posture add to an overall firm expression. The man is wearing a vest or jacket resembling a doublet (a jacket type worn from the late medieval period through the 17th century in Europe). A broad collar and cuffs appear over the neck of the jacket and the ends of the sleeves, respectively. A textured belt with a semi-circular buckle is depicted around the figure's waist. The sitter appears to be wearing pants or some form of breeches made of a garment decorated with floral patterns. The man is depicted in front of a desk; his left hand extended touching what could be a document or a book. A ring is clearly depicted on his left index finger. With his right hand, he is holding a quill as if he is ready to sign or write on what is placed on the desk. An ink bottle with another quill is depicted at the edge of the desk. Behind the standing figure, evidence of heavy drapery, possibly curtains, suggests the setting of a richly furnished interior room which could be the depicted man's study considering the presence of the desk. Thin chains, seemingly decorated with beads or pearls, appear to support a lighting device hanging behind the left side of the man's head. Overall, the portrait depicts a middle 
age professional man, possibly a merchant, a banker or an account keeper of some sorts, posing in his study with the attributes of his status and occupation, book, ink, quill as well as his upper class attire, clearly represented.

The belt buckle and the slightly curved line of the drapery fold in the underpainting are recognizable on the upper painting by close visual examination suggesting a small thickness of the pictorial layer(s) of the Ecce Homo. Moreover, the applied microscopy analysis of the painting stratigraphy revealed no intermediate layer between the upper and the lower paintings suggesting that the Ecce Homo was painted directly on the underlying portrait.

\section{Painting stratigraphy}

Visual examination of the side edge of the painting revealed the presence of two canvases. A new canvas was likely added on the back of the original one for support. Microscopy observations confirmed that the original canvas was prepared with a white layer, which was identified by XRF analysis to be a calcium sulphate, anhydrous or gypsum. The low intensity $\mathrm{Pb}$ lines indicate admixtures of lead white in the preparation layer. As suggested by multiple microscopy observations, the male portrait was overpainted directly with the Ecce Homo composition with no evident intermediate layer between the two paintings. ${ }^{1}$

\section{Pigment analysis \\ Flesh tones}

Based on the results of XRR, the flesh tones of the underlying portrait were expected to be found in the areas of man's face and hands. These parts of the hidden portrait correspond to the crossed arms of Christ and the dark brown background behind him on the Ecce Homo, respectively. Microscopy analysis of cracks and flaked paint in both areas allowed the observation of the flesh tones of the underlying portrait. Figure 2 shows microscopy images taken from the area of man's forehead (Fig. 2a) and his left hand (Fig. 2b, c). The dark spots on both images are related to the damaged pictorial layer of the Ecce Homo: in Fig. 2a, it is the dark brown shade of Christ's left hand; in Fig. 2b, c, it is the dark brown background behind Christ. The light brown areas on the microscopy images represent the flesh tones of the underlying painting. The flaking of the Ecce Homo dark layer in these areas is not even, but follows the pattern of the canvas as demonstrated in Fig. 2b. Despite the

\footnotetext{
${ }^{1}$ It should be noted however, that during the painting's restoration, Ms Sarah Walden cautiously suggested the possibility of the presence of a dark thin film between the two compositions. Unfortunately, this observation could not be substantiated with the use of digital microscopy in selected cracks of the upper painting.
}

presence of a thick ground, the canvas surface is not completely smooth. The dark layer of the Ecce Homo is missing on intersections of the canvas' threads which were more exposed to wear. In addition, the Ecce Homo layer in this area is thinner than in the area of Christ's crossed arms, where the paint was applied more thickly. This caused more extensive damage of the upper painting thus revealing larger areas of the underlying portrait. Both areas of the flesh tones were painted with a complex pigment mixture containing white, red, brown and green pigments. The white pigment has coarse rounded particles. Coarse to fine angular black particles can be distinguished in Fig. 2a. Admixtures of the red pigment can be observed by the bright red crystals of angular shape. Rare green crystals of coarse size can also be seen in Fig. 2c, revealing the presence of green pigment in the pigment mixture of the flesh tones.

$\mathrm{X}$-ray fluorescence analysis revealed the presence of $\mathrm{Pb}$ attributed to lead white $\left(2 \mathrm{PbCO}_{3} \cdot \mathrm{Pb}(\mathrm{OH})_{2}\right)$, whose coarse white particles were observed with microscopy. The attribution of $\mathrm{Pb}$ to red lead $\left(\mathrm{Pb}_{3} \mathrm{O}_{4}\right)$ was excluded by microscopy observations, which did not detect its typical red to orange aggregates of fine particles. Figure $7 \mathrm{a}$ shows variable intensity of the $\mathrm{Pb} \mathrm{L} \alpha$ line depending on the analysed spot. Elevated counts can be seen on spots located within the contours of man's hand and face. A similar tendency can be observed for $\mathrm{Hg} \mathrm{L} \alpha$ line (Fig. 7b) indicative of vermilion $(\mathrm{HgS})$, whose angular red crystals were detected by microscopy. Umber is likely the brown pigment added to the mixture of lead white and vermilion to produce flesh tones. This is evidenced by slightly elevated Fe and Mn counts (Fig. 7c, d, respectively). The qualitative analysis of XRF spectra suggests admixtures of a copper green pigment in the flesh tones, however, its precise nature (e.g. malachite, verdigris, resinate) can be identified using the methods of structural analysis such as XRD or FTIR on cross-sections.

\section{Red areas}

Close visual examination of the Ecce Homo painting surface as well as the microscopy observations of cracked and flaked spots have revealed large areas of red colour on the underlying portrait. With the naked eye, it is possible to clearly distinguish two long, slightly bent lines visible on the Ecce Homo (Fig. 1a): one passes across the columns in the background of the Ecce Homo and located above Pilate's left hand and a second passes across Pilate's dress, beginning from the very bottom edge of the Ecce Homo painting. These lines are attributed to the background drapery of the hidden portrait as they are not related to any compositional element of the Ecce Homo. In these areas, the pictorial layer of the upper painting has undergone significant damage 

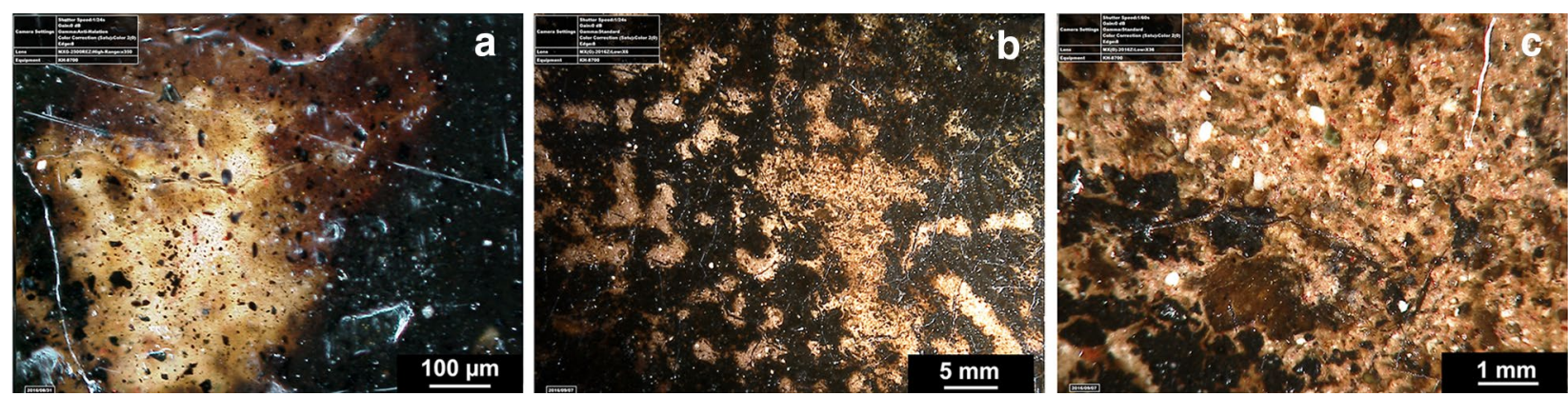

Fig. 2 Microscopy images taken from the Ecce Homo surface. The images reveal flesh tones of the hidden portrait visible through cracks and flaked areas: a flesh tone of the man's forehead and corresponding dark tone of Christ's left hand; $\mathbf{b}$ and $\mathbf{c}$ flesh tones of the man's left hand and corresponding dark brown background behind Christ

allowing the compositional elements of the lower work to become visible on the upper one. Microscopy images taken from various locations of the background drapery (Fig. 3) show a red pigment underlying the Ecce Homo. These images demonstrate that depending on the analysed spot, the red pigment of drapery has various colour tones: opaque red-brown pigment with fine particles can be seen in Fig. 3a, b; the same pigment with admixtures of yellow, shiny, angular crystals in Fig. 3b; transition of red to white in Fig. 3c highlighting the illuminated drapery folds.

Iron oxide is the main component of the red pigment used for the background drapery. It is evidenced by elevated Fe counts on spots within the contours of drapery (Fig. 7c). Generally, XRF analysis permits the distinction between pure iron oxide (hematite) and red ochre by the detection of $\mathrm{Si}, \mathrm{Al}, \mathrm{Ti}$ and $\mathrm{Mn}$ lines in XRF spectra of the latter. However, in the case of the hidden painting, the detection of low- $Z$ elements was not possible because of the attenuation of the signal by the upper painting and the varnish layer(s). As for Mn, its omnipresence in XRF spectra is likely due to the upper painting, which appears dark brown in the majority of the analysed spots. These limitations of XRF elemental analysis allow the identification of only general types of red pigments based on red iron oxide in the case of hidden paintings, whereas a more precise assignment as hematite or red ochre would be possible on the analysis of painting cross-sections. Depending on the analysed spot, the XRF spectra from the drapery spots are featured by low intensity $\mathrm{Hg}$ and $\mathrm{As}$ lines, suggesting admixtures of vermilion and orpiment, respectively. The identification of orpiment is also supported by the detection of shiny yellow crystals on the highlighted drapery folds by digital microscopy. Along with orpiment, lead white was likely used for the highlighted drapery folds and the light shade of the diagonal line visible to the right from man's figure.

The red colour was also detected in the area below the neck of the male figure of the hidden portrait. Microscopy analysis of cracks in the area of the tissue held by Christ revealed an underlying bright red layer (Fig. 4) occupying the area under man's neck and expanding to a few $\mathrm{cm}$ below. The red pigment in this area represents a mixture of bright, dark red crystals of angular shape

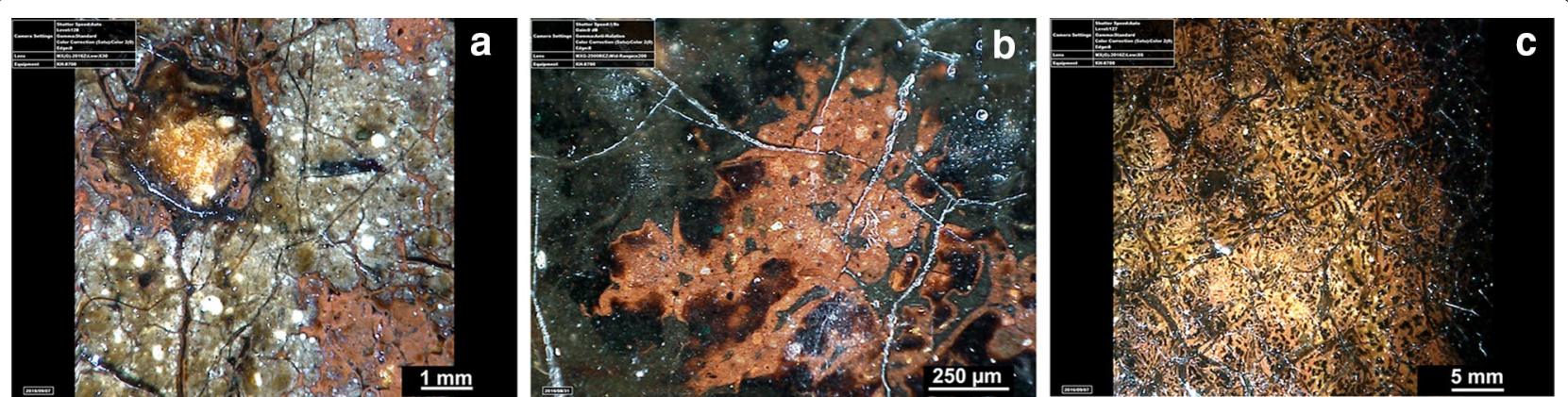

Fig. 3 Microscopy images taken from the Ecce Homo surface. The images reveal the colour of background drapery of the hidden portrait visible through cracks and flaked areas in Ecce Homo: a red pigment of drapery and corresponding yellow colour of the columns of the Ecce Homo; b red pigment of drapery with admixtures of a yellow pigment and corresponding dark colour of Pilate's dress of Ecce Homo; chighlighted fold of drapery visible through heavily damaged dark layer of Ecce Homo 


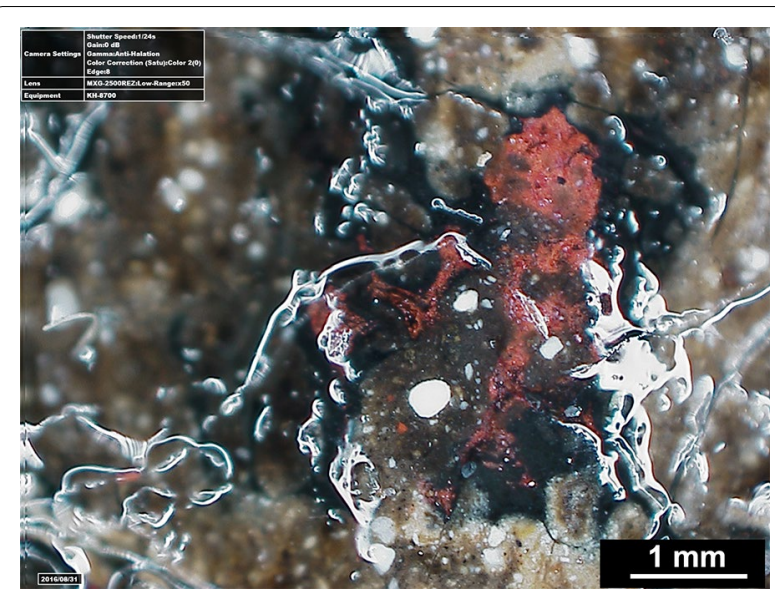

Fig. 4 Microscopy image of the Ecce Homo surface. The image reveals bright red colour of the hidden portrait under man's chin and corresponding light flesh colour of Christ's hand

and red-orange opaque particles of fine size. Thorough examination of the XRR image in this area does not permit the detection of any compositional elements belonging to the underlying portrait. Thus, the presence of a red element on the man's dress, possibly a garment such as a scarf, tied around his neck could only be confirmed by microscopy. Figure 5a shows two XRF spectra taken from the area of the red garment (spot 29) and from outside the red garment (spot 20). The upper painting has equal contribution in both spectra as both spots analysed lie within the same homogeneous area of Christ's hand (Fig. 1a). Thus, the detection of $\mathrm{Hg}$ indicative of vermilion in the spot 29 is attributed to the red garment of the hidden portrait. Analysis of other spots within this area confirmed the presence of vermilion as evidenced by the elevated $\mathrm{Hg}$ counts (Fig. 7b). The red-orange component observed with microscopy could be red iron oxide or red lead. However, these assumptions cannot be confirmed with XRF analysis. The spectra do not show any difference in the Fe line intensity between spots 20 and 29. As for $\mathrm{Pb}$ line, there is a strong interference from lead white in the flesh tones of the upper painting.

\section{White areas}

The bright areas on the X-radiography image indicate the presence of X-ray opaque pigments. Close microscopy observations of cracks in these areas revealed a white pigment underlying the Ecce Homo. The small thickness of the Ecce Homo pictorial layers facilitated the detection of the majority of the white details of the underlying portrait by visual examination and microscopy observations of the Ecce Homo surface. These include three thick white lines corresponding to the highlights of what was identified as a ring on the man's index finger, the white brush strokes corresponding to the edge of the desk in the lower right corner of the portrait, the white round painterly details, which were suggested to be the representation of beads or knots behind the man's figure, a fragment of the belt buckle, the edge of the book in the right lower corner of the underlying portrait and the side of the same book, the tip of the quill, held by the right hand of the man, the collar and the the cuffs of the represented figure.

Figure $5 \mathrm{~b}$ shows XRF spectra taken from the area of the man's right cuff (spot 5) and from outside the cuff (spot 6). The contribution of the upper painting to both spectra is expected to be the same, since it corresponds to a homogeneous dark background on the left from Christ's figure (Fig. 1a). Thus, the much higher intensity of $\mathrm{Pb}$ lines in the spectrum of spot 5 compared to spot 6 suggests the use of lead white for the right cuff. Point XRF analysis of $\mathrm{Pb}$ line on other white areas of the hidden portrait (Fig. 7a) confirms the use of lead white.

\section{Dark areas}

Microscopy analysis revealed a dark colour on the man's dress. Specifically, a dark layer under the Ecce Homo was noticed on all spots corresponding to the area of man's dress. The microscopy images in Fig. 6a show the flesh tones of Christ's skin of the Ecce Homo and the dark colour of the dress of the male figure visible through cracks. The contours of the dress are also detectable with the naked eye in some areas of the Ecce Homo, where its pictorial layer is thin. The microscopy image in Fig. 6b taken from the area of Pilate's dress shows a distinct border in the lower paint layer: the dark right side of the image corresponds to the sleeve of the dark dress and the light left side is the background drapery of the underlying portrait. The upper greenish brown layer corresponds to the colour of Pilate's dress on the same spot of the Ecce Homo. The entire area of the figure's dress appears to be dark on the XRR image allowing the exclusion of X-ray opaque pigments. The low Fe and Mn counts (Fig. 7c, d) also exclude umber. XRF spectra taken from multiple spots inside and outside the area of dress do not demonstrate any difference in the elemental composition suggesting carbon black. Based on microscopy results, we can exclude the presence of flame black, since the black pigment has coarse and angular particles indicating char or coke. The presence of ivory black is also excluded due to the absence of P lines in the XRF spectra.

The desk represented in the lower right corner of the hidden portrait has grey colour with a green hue recognizable from microscopy images (Fig. 6c). The pigments used for the desk have very fine particles complicating the distinction of the components of the pigment mixture with microscopy. Figure 5 c shows XRF spectra taken from the area of the desk (spot 128) and from outside this 


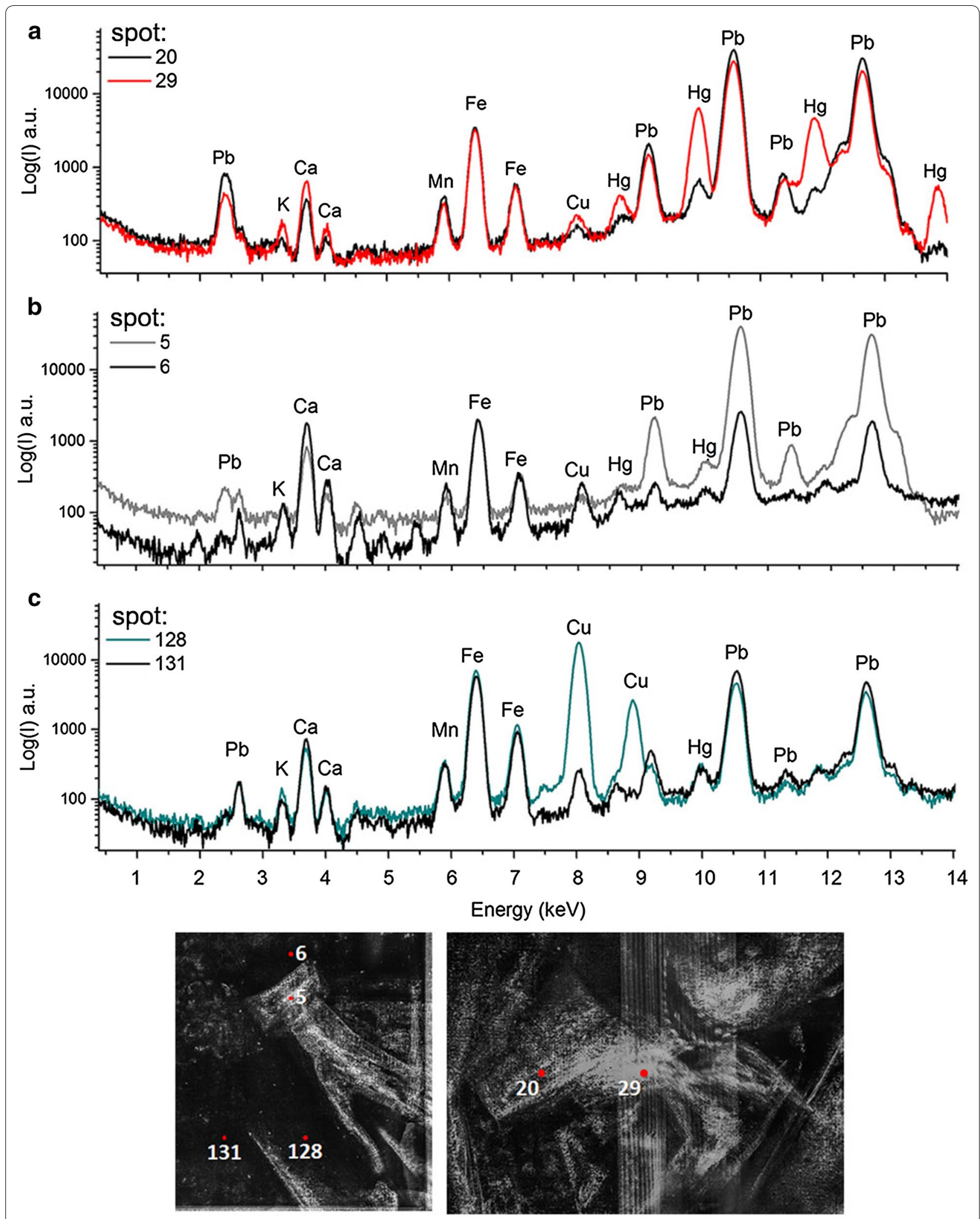

Fig. 5 Example XRF spectra showing the identification of $\mathbf{a}$ vermilion on the red garment, $\mathbf{b}$ lead white on the right cuff and $\mathbf{c}$ copper green on the desk of the hidden portrait 

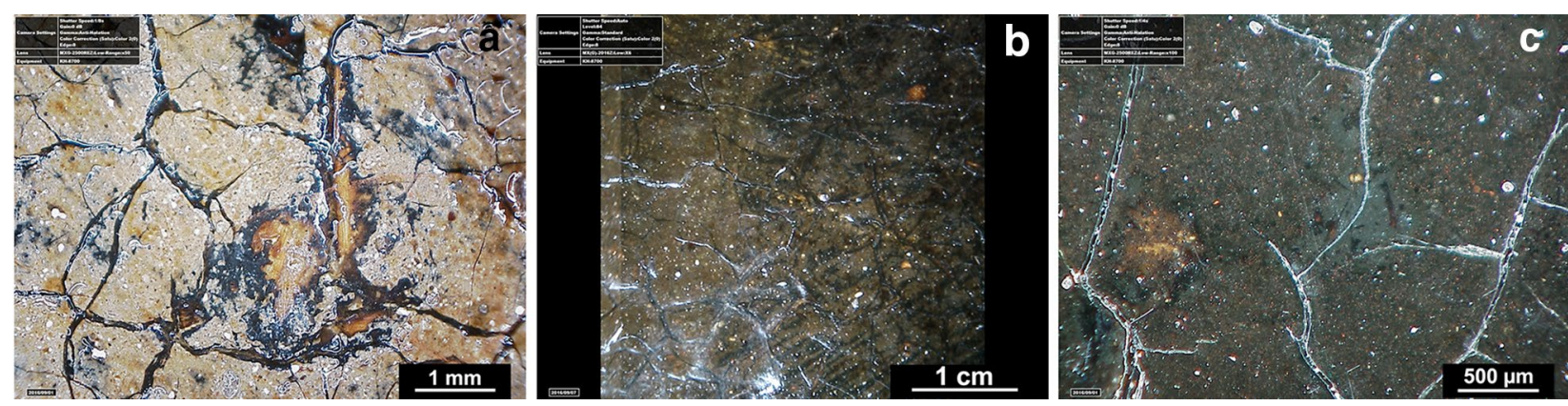

Fig. 6 Microscopy images taken from the Ecce Homo surface. The images reveal dark areas of the hidden portrait visible through cracks and flaked areas: a dark colour of man's dress and corresponding light flesh tones of Christ's skin; b boundary man's dark dress-background drapery and corresponding dark brown colour of Pilate's dress; c greenish grey colour of the desk and corresponding brown background behind Christ

area (spot 131). The intense $\mathrm{Cu}$ lines in spot 128 suggest the presence of a copper green pigment explaining the greenish hue observed with microscopy. The area of the desk is the only studied area of the hidden portrait that exhibits elevated $\mathrm{Cu}$ counts (Fig. 7e). The green pigment can be identified by destructive methods on painting cross-sections. Based on the results of the non-invasive analysis and previous analyses of Titian's works [20-22], one may suggest copper resinate, verdigris and malachite as possible candidates for the green pigment, whose nature can be identified using the methods of structural analysis.

\section{Conclusions}

The case study analysed is a male portrait overpainted with an Ecce Homo attributed to Titian's studio. The results of its study demonstrate the potential as well as the limitations of an integrated use of XRR, micro-XRF and digital microscopy to the study of hidden paintings. In particular, the study exemplified the potential of applying digital microscopy to the study of painting's stratigraphy, also as an alternative tool to destructive analysis on cross-sections. The study also demonstrates the possibility to perform the preliminary pigment identification of hidden pictorial layers with micro-XRF analysis without an XRF scanner. The outcome of this study is of particular interest for conservation laboratories and art characterization groups with limited scientific infrastructure and focusing on non-invasive and non-destructive methods of diagnostics.

The painting's stratigraphy was studied with microscopy observations of sub-surface layers through cracks and damages in the upper pictorial layer, revealing a complex stratigraphy. From the lowermost to the uppermost layer: newer canvas, original canvas, ground layer (calcium sulphate), male portrait, Ecce Homo, varnish. Results have indicated that the Ecce Homo was painted directly on the underlying portrait without an intermediate preparatory layer between the lower (earlier) and the upper (later) compositions.

The composition of the hidden portrait was thoroughly examined by XRR. This process permitted the definition of its compositional elements and consequently of the areas requiring further pigment analysis by micro-XRF. Microscopy analysis has allowed the mapping of the colour scheme, whereas the preliminary pigment identification (Table 1 ) was carried out by micro-XRF.

The results of this study have shed light on key aspects of the artists' painting technique as reflected in the close 'stratigraphic' relation of the two paintings. Preliminary observations suggest that the existence of the almost completed portrait on the canvas affected the execution of the Ecce Homo composition. Details of the underlying work seem to have influenced what was painted over it. An instructive example of the relation between underpainting and overpainting can be observed in the Ecce Homo painting area of the tied hands of Christ, which was painted over the face of the underlying composition. Future art historical analysis of the work will provide a better and more detailed understanding of the relation of the two paintings. A particularly interesting aspect of this relation will be the study of the ways the pigment scheme of the underlying portrait was used or simply influenced the colouring synthesis of the Ecce Homo. From an art historical point of view, the systematic comparison of the painterly composition and colouring schemes of the two paintings promises exciting results related to the history, dating, technique and attribution of the works. As mentioned above, the elemental analysis of the two paintings has provided results showing that the pigments used are compatible with those used by artists in the period of Titian's artistic activity in the 16th century. In addition, the further study of the work 

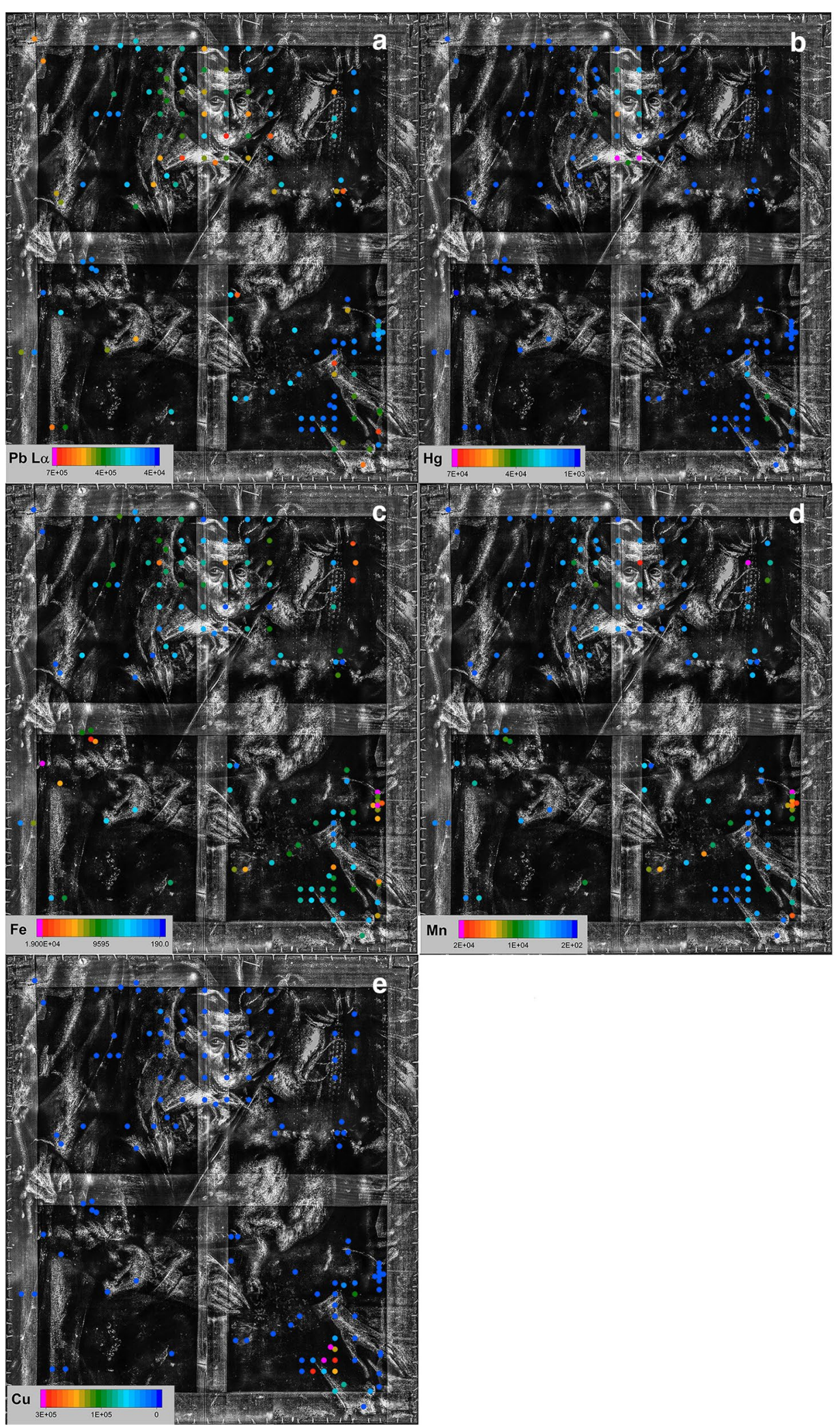

Fig. 7 Multiple point analysis by micro-XRF. The dots plotted on XRR image indicate the location of spots measured with micro-XRF. The dot's colour corresponds to the peak area of XRF lines: a Pb La, b Hg La, c Fe Ka, $\mathbf{d} \mathrm{Mn} \mathrm{Ka}$ and $\mathbf{e} \mathrm{Cu} \mathrm{Ka}$; The magenta indicates high counts; the blue indicates low counts 
Table 1 Suggested colours and pigments based on non-invasive examination

\begin{tabular}{lll}
\hline Basic color & Compositional elements & Suggested pigments \\
\hline Red & $\begin{array}{l}\text { Background drapery } \\
\text { Red element of man's dress under the collar, presumably scarf }\end{array}$ & Red iron oxide, vermilion. Orpiment and lead white for highlights \\
White & $\begin{array}{l}\text { Collar, cuffs, highlights of the desk and the book, quill, beads, belt } \\
\text { buckles, highlights of the dress }\end{array}$ & Lead white \\
Black & Man's dress & Carbon black (char or coke) \\
Grey & Desk & Carbon black (char or coke), lead white, copper green \\
Flesh tones & Man's face and hands & Vermilion, lead white, umber, copper green \\
\hline
\end{tabular}

will offer a better understanding of the process of the reuse of canvases in Renaissance workshops, which was seemingly common practice. Hence, the comparative study of the two paintings has great potential for art historical analysis and will be pursued as the next step of our study.

\section{Abbreviations}

XRR: X-ray radiography; IRR: infrared reflectography; THz: terahertz; XRF: X-ray fluorescence; NAAR: neutron activation autoradiography; CCD: charge coupled device; FWHM: full width at half maximum.

\section{Authors' contributions}

SG performed the data acquisition, analysis and interpretation. She was the lead author of the article's text. NB was responsible for the art-historical description and analysis of the paintings, contributed to the interpretation of $\mathrm{X}$-ray radiography images and wrote and edited the related parts of the article. SH was responsible for setting-up the methodological and scientific framework, in particular the integration of data from various measurements, the strategy for selecting the measurements spots and the characterisation of the overall stratigraphy of the painting. All authors edited the final manuscript. All authors read and approved the final manuscript.

\section{Authors' information}

SG is a postdoc at The Cyprus Institute. She studied Physical Chemistry and received her Ph.D. in Analytical Chemistry. Her research concentrates on chemical characterization of artifacts and works of art (Polychromed archaic statues, Terracotta figurines, Roman wall paintings, Byzantine manuscripts and icons, Canvas paintings) with the focus on pigment analysis using nondestructive analytical techniques.

NB is an Associate Professor at The Cyprus Institute. He specializes in the field of Medieval, Byzantine and Early Modern Art and Architecture; Heritage of the Built Environment; Heritage in Contested and Divided Cities; Byzantine Monasticism. He is also directing Cyl's Imaging Cluster for Archaeology and Cultural Heritage (ICACH).

$\mathrm{SH}$ is an Associate Professor at The Cyprus Institute. His research interests are computer applications to archaeology, in particular ontologies, 3D scientific visualization, semantic structures and archaeological digital documentation. He is the director of STARLAB, a mobile laboratory facility for heritage sciences, performing in situ physic-chemical measurements and digital documentation and analysis on archaeological sites, heritage monuments, artefacts and works of art.

\section{Acknowledgements}

The present study is part of a larger research initiative in 'Art Characterization' led by the Science and Technology in Archaeology Research Center of the Cyprus Institute. The authors would like to thank Dr. Andreas Pittas for permitting the scientific study of the Ecce Homo painting. The authors also acknowledge the generous contribution of Dr. Photis Kollas and the Mediterranean Hospital Limassol in the acquisition of the $X$-ray radiography images as well as Dr. Ioannis Artopoulos for his expert advice. Many thanks go to Ms Sarah
Walden who conserved the painting and provided invaluable observations and suggestions. The authors express their gratitude to Ropertos Georgiou and Giusi Sorrentino from The Cyprus Institute, the first for leading the technical photography of the work and supplying the visible imaging of the painting and the second for her assistance in data acquisition. The authors also thank Panayiotis Kyriakou for processing and refining the $X$-ray radiography image.

\section{Competing interests}

The authors declare that they have no competing interests.

\section{Availability of data and materials}

All the raw data can be accessed at https://www.dropbox.com/sh/ myxq4f6zv90v74h/AADVK8PR_1fz4BUOBmG20hyXa?dl=0.

\section{Funding}

The study did not receive any financial support.

\section{Publisher's Note}

Springer Nature remains neutral with regard to jurisdictional claims in published maps and institutional affiliations.

Received: 17 January 2017 Accepted: 5 July 2017

Published online: 24 July 2017

\section{References}

1. Thurrowgood D, Paterson D, de Jonge MD, Kirkham R, Thurrowgood S, Howard DL. A hidden portrait by Edgar Degas. Sci Rep. 2016. doi:10.1038/ srep29594.

2. Trentelman K, Janssens K, van der Snickt G, Szafran Y, Woollett AT, Dik J. Rembrandt's an old man in military costume: the underlying image re-examined. Appl Phys A Mater Sci Process. 2016. doi:10.1007/ s00339-015-9426-3.

3. Alfeld M, Broekaert JAC. Mobile depth profiling and sub-surface imaging techniques for historical paintings - a review. Spectrochim Acta Part B At Spectrosc. 2013. doi:10.1016/j.sab.2013.07.009.

4. Alfeld M, Janssens K. The rediscovered portrait of Prospero Farinacci by Caravaggio. Artibus et Historiae. 2016;73:1-37.

5. Reiche I, Müller K, Mysak E, Eveno M, Mottin B. Toward a three-dimensional vision of the different compositions and the stratigraphy of the painting L'Homme blessé by G. Courbet: coupling SEM-EDX and confocal micro-XRF. Appl Phys A Mater Sci Process. 2015. doi:10.1007/ s00339-015-9428-1.

6. Schalm O, Vanbiervliet L, Willems P, De Schepper P. Radiography of paintings: limitations of transmission radiography and exploration of emission radiography using phosphor imaging plates. Stud Conserv. 2014;59:1023. doi:10.1179/2047058413Y.0000000088.

7. Faries M. Analytical capabilities of infrared reflectography: an art historian's perspective. In: National Academy of Sciences, editor, Scientific examination of art: modern techniques in conservation and analysis, Papers of the Arthur M. Sackler Colloquium of the National Academy of Sciences. Washington D.C.: National Academies Press; 2005. p. 87-104. 
8. Abraham E, Younus A, Delagnes JC, Mounaix P. Non-invasive investigation of art paintings by terahertz imaging. Appl Phys A. 2010;100:585-90. doi:10.1007/s00339-010-5642-z.

9. Adam AJL, Planken PCM, Meloni S, Dik J. TeraHertz imaging of hidden paint layers on canvas. Opt Express. 2009;17(5):3407-16.

10. Ainsworth MW, Egbert H-B, Brealey J, Meyers P. Art and Autoradiography: Insights into the Genesis of Paintings by Rembrandt, Van Dyck, and Vermeer. Metrop Mus Art. ISBN: 0-87099-286-4 1982.

11. Seim C, Laurenze-Landsberg C, Schröder-Smeibidl B, Mantouvalou I, de Boer C, Kanngießer B. Old traces, read anew - "The Reading Hermit" painting in the light of X-ray fluorescence. J Anal At Spectrom. 2014 doi:10.1039/C3JA50301A

12. Anitha A, Brasoveanu A, Duarte M, Hughes S, Daubechies I, Dik J, Janssens K, Alfeld M. Restoration of X-ray fluorescence images of hidden paintings. Sign Process. 2013. doi:10.1016/j.sigpro.2012.09.027.

13. Martins A, Coddington J, Van der Snickt G, van Driel B, McGlinchey C, Dahlberg D, Janssens K, Dik J. Jackson Pollock's Number 1A, 1948: a noninvasive study using macro-X-ray fluorescence mapping (MA-XRF) and multivariate curve resolution-alternating least squares (MCR-ALS) analysis. Herit Sci. 2016. doi:10.1186/s40494-016-0105-2.

14. Howard DL, De Jonge MD, Lau D, Hay D, Varcoe-Cocks M, Ryan CG, Kirkham R, Moorhead G, Paterson D, Thurrowgood D. High-definition $\mathrm{X}$-ray fluorescence elemental mapping of paintings. Anal Chem. 2012. doi:10.1021/ac203462h.

15. Legrand S, Vanmeert F, Van der Snickt G, Alfeld M, De NolfW, Dik J, Janssens K. Examination of historical paintings by state-of-the-art hyperspectral imaging methods: from scanning infra-red spectroscopy to computed X-ray laminography. Herit Sci. 2014;2:13.
16. Cabal A, Schalm O, Eyskens P, Willems P, Harth A, Van Espen P. Comparison of $X$-ray absorption and emission techniques for the investigation of paintings. X-Ray Spectrom. 2015. doi:10.1002/xrs.2591.

17. Ioannides P. 2015. https://www.dorotheum.com/en/auctions/currentauctions/kataloge/list-lots-detail/auktion/11382-old-master-paintings/ lotID/39/lot/1950682-studio-of-tiziano-vecellio-called-titian.html. Accessed 14 Apr 2016.

18. Falomir M. Christ Mocked, a Late "Invenzione" by Titian. Artibus et Historiae. 2007;28(55):53-61.

19. Nygren CJ. Titian's Ecce Homo on Slate: stone, oil, and the transubstantiation of painting. Art Bull. 2017;99:36-66

20. Birkmaier U, Wallert A, Rothe A. 1995. Technical Examinations of Titian's Venus and Adonis: a note on early Italian oil painting technique. In: Conference proceedings, historical painting techniques, materials, and studio practice. ISBN: 0892363223

21. Lucas A, Plesters J. Titian's Bacchus and Ariadne: an account of the condition, conservation, materials and techniques. Natl Gallery Tech Bull. 1978;2:25-47.

22. Dunkerton J, Spring M, Billinge R, Kalinina K, Morrison R, Macaro G, Peggie D, Roy A. Titian's painting technique to c.1540. Natl Gallery Tech Bull. 2013;34:4-31.

\section{Submit your manuscript to a SpringerOpen ${ }^{\circ}$ journal and benefit from:}

- Convenient online submission

- Rigorous peer review

- Open access: articles freely available online

- High visibility within the field

- Retaining the copyright to your article

Submit your next manuscript at $\boldsymbol{s p r i n g e r o p e n . c o m ~}$ 